\title{
El populismo según Ernesto Laclau: problemas en la definición de un concepto
}

Elkin Andrés Heredia

Pontificia Universidad Javeriana, Colombia

(c) $\underset{\mathrm{Br}}{\mathrm{i}}$ 


\title{
El populismo según Ernesto Laclau: problemas en la definición de un concepto*
}

\begin{abstract}
Resumen: reconociendo la actualidad e interés que posee y suscita el fenómeno del populismo, se propone buscar la definición que brinde mayor claridad y utilidad. De esta manera se comienza por exponer los presupuestos del populismo tal como lo entiende Ernesto Laclau. Posteriormente, se señalan los vacíos que tiene su propuesta. Así, se llega a la perspectiva de Jacques Rancière, para entender la política como una práctica de inclusión radical, que es utilizada para dar respuesta a las críticas de falta de especificidad que se le hacen al pensador argentino y se señalan los posibles problemas que pueden encontrarse en los planteamientos de diferentes comentaristas. Finalmente, se plantea que el populismo es un fenómeno democrático y además un proceso de inclusión radical, aseveración que se apoya a partir de la comprensión de la democracia como una transformación histórica. Esta definición pretende ser una superación de los problemas de abstracción y excesiva especificidad que han sido rasgos distintivos de las investigaciones realizadas alrededor del concepto de populismo, que brinde mayor claridad al momento de analizar casos concretos.
\end{abstract}

Palabras clave: populismo, Laclau, Rancière, democracia.

\section{Populism According to Ernesto Laclau: problems in defining A Concept}

\begin{abstract}
: recognizing the actuality and interest that has and provokes the phenomenon of populism, it is proposed to seek the definition that provides greater clarity and utility. In this way we begin by exposing the presuppositions of populism as understood by Ernesto Laclau. Subsequently, the gaps in your proposal are indicated. Thus, we come to the perspective of Jacques Rancière, to understand politics as a practice of radical inclusion, which is used to respond to criticisms of lack of specificity that are made to the Argentine thinker and pointed out the possible problems that can have the approaches of different commentators. Finally, it is argued that populism is a democratic phenomenon and also a process of radical inclusion, an assertion based on the understanding of democracy as a historical transformation. This definition pretends to be a surpassing of the problems of abstraction and excessive specificity that have been distinctive features of the investigations carried out around the concept of populism that provides more clarity when analyzing concrete cases.
\end{abstract}

Keywords: populism, Laclau, Rancière, democracy.

Fecha de recepción: 21 de abril de 2017

Fecha de aceptación: 8 de septiembre de 2017

Forma de citar (APA): Heredia, E. (2018). El populismo según Ernesto Laclau: problemas en la definición de un concepto. Revista Filosofía UIS, 17(1), doi: http://dx.doi.org/10.18273/revfil. v17n1-2018009

Forma de citar (Harvard): Heredia, E. (2018). El populismo según Ernesto Laclau: problemas en la definición de un concepto. Revista Filosofía UIS, 17(1), 181-203.

Elkin Andrés Heredia: colombiano. Magíster en estudios políticos, Pontificia Universidad Javeriana. Profesional en filosofía y letras, Universidad de Caldas.

Correo electrónico: elkin.heredia@udea.edu.co

* Artículo de reflexión derivado de investigación. 


\section{El populismo según Ernesto Laclau: problemas en la definición de un concepto}

\section{Introducción}

La llegada al poder de Trump, las amenazas ultraderechistas en Europa, el ascenso de Podemos en España, las decisiones inesperadas en Colombia e Inglaterra por parte del soberano supremo, condujeron a un cuestionamiento masivo en torno a la palabra y al fenómeno conocido como "populismo". Aunque este renovado interés obedece principalmente al interés de los medios por la figura del multimillonario presidente de los Estados Unidos, el cuestionamiento dejó en evidencia la falta de consenso y la diversidad de definiciones que se pueden llegar a plantear en torno al populismo. En Latinoamérica la figura de Maduro concentra toda la atención a la hora de brindar un significado, por lo que discursos fundados moralmente como los de Gloria Álvarez, autora del bestseller El engaño populista, de una pobreza conceptual realmente profunda, han resultado Ilamativos ante la preocupación que suscita Venezuela. El hecho de que el fenómeno del populismo pueda tener un contenido ideológico de izquierda como de derecha colabora para la confusión. El New York Times (26 de diciembre de 2016), tras la victoria de Trump en noviembre, encendía las alarmas, señalando la incompatibilidad histórica que existe entre democracia y populismo. Pero: ¿es realmente el populismo antidemocrático? Más allá de lo planteado en los debates televisivos, en la infinidad de columnas de opinión o en la diversidad de adjetivaciones empleadas por los propios políticos, el problema del populismo ha sido estudiado desde diversos enfoques metodológicos, a partir de diversos referentes empíricos, desde hace setenta años, y por ende, ha sido definido de diversas maneras. Desde un plano conceptual: ¿̇cuál sería la definición más adecuada? Pensando en la necesidad de distinguir los casos de populismo de otro tipo de fenómenos políticos: ¿qué concepción puede tener una mayor capacidad explicativa? El enfoque adoptado por Ernesto Laclau (1935-2014) resulta importante porque cuestiona la mayor parte de los supuestos tradicionales de la política moderna. Una lectura detallada y crítica de la propuesta de Laclau permite acceder a una definición que afirme que un conocimiento de su postura 
proporcionaría una nueva herramienta para alcanzar un nuevo nivel de discusión. Este artículo se propone, entonces, esta tarea. Sin desconocer, por supuesto, que la misma propuesta de Laclau está sujeta a diversas críticas.

\section{El problema con la definición del populismo}

"«Populismo» es un concepto a la vez elusivo y recurrente" (Laclau, 1985, p. 165). Este par de características obligan a la hora de pretender analizar el fenómeno tener presente que se trata de un tópico que suscita la ambigüedad y atrae interpretaciones contradictorias. Un ejemplo clásico de esta contradicción es el que tiene que ver con su carácter democrático o antidemocrático. Para pensadores como Margaret Canovan (1999) el hecho de que el populismo resalte la soberanía popular lo hace una expresión privilegiada de la democracia. Pero al mismo tiempo, trabajos como el de Abst y Rummens (2007), consideran la centralidad del líder y la mistificación de las masas como un grave problema que entorpece la democracia, ya que esta se caracteriza — siguiendo a Lefortcomo el acontecimiento que le otorga un lugar perpetuamente vacío al poder. En este mismo sentido, como lo han demostrado los recientes acontecimientos en Estados Unidos y Europa, el populismo no se inclina inexorablemente por alguna tendencia ideológica en concreto ${ }^{1}$, mucho menos por algún modelo económico.

Esta recurrente y frustrante imposibilidad de delimitar los alcances teóricos de la noción de populismo, ha llevado a algunos autores a proponer su eliminación del léxico de las ciencias sociales (Roxborough, 1984, p. 14); a otros a decir que se trata de un "invento" contraproducente propio de la imaginación de sociólogos y politólogos (Olivera, 2005). No ha faltado quien ha expresado un pesimismo radical: "Quien acude a la literatura académica existente para aclararlo, no encuentra por lo tanto nada que decir al respecto en un plano conceptual" (Hermet, 2003, p. 5). Ante este panorama, la utilidad metodológica para analizar casos concretos, que podría brindar una definición positiva de populismo, resulta ausente ante una realidad que aparentemente excede las capacidades de la racionalidad moderna ${ }^{2}$.

\footnotetext{
No es posible decir que el populismo sea ideológicamente de derecha o de izquierda. Casos como el de Margaret Thatcher, y más recientemente, el de Jean Marie Le Pen, el Partido del Progreso noruego, el partido ATAKA de Bulgaria y hasta el mismo Trump, nos hablan de un populismo conservador y de derecha, que se puede componer de elementos xenófobos y neoliberales. Rasgos que no aparecen en las definiciones clásicas del populismo, que lo caracterizaban como esencialmente socialista e incluyente.

${ }^{2}$ Una crítica recurrente es la de que se trata de un falso problema. Para Laclau, en la indeterminación conceptual del populismo radica precisamente su atractivo investigativo. Lo que puede mostrar el populismo es la incapacidad de la racionalidad moderna, plasmada en las metodologías positivistas de las ciencias sociales, de construir un discurso explicativo; y al mismo tiempo, es el síntoma del anquilosamiento de esta misma tradición en presupuestos esencialistas que va unido a una obsesión por postular marcos universales de comprensión que desconocen los procesos ubicados en historias diversas. No poder
} 
Echando un vistazo a la historia de lo que se ha dicho sobre el populismo, resulta evidente que el debate ha acontecido en medio de la confrontación de dos líneas paralelas: por un lado, la de la especificidad; y por el otro, la de la generalidad (Mckinnon y Petrone, 1999, p. 13). Algunos autores privilegian la búsqueda de la especificidad, por eso plantean que el populismo es un fenómeno ligado a ciertas condiciones de aparición — fundamentalmente económicas — que ya fueron y no volverán (Vilas, 2004). Lo importante para ellos es recoger una serie de atributos empíricamente constatables, a partir de los cuales se emplea el camino de la inducción, llegando finalmente a determinar lo que es el populismo desde una perspectiva empírico-histórica (Panizza, 2009, p. 11). El problema con el que se encuentran los que toman este camino es que por ir tras lo específico terminan cayendo en una parcialización arbitraria, que les impide trasladar la estructura explicativa a nuevos contextos. Han creado un concepto, que en los términos de Sartori, es incapaz de "viajar" (Sartori, 2011, p. 200).

Al otro lado se encuentran las posturas que se preguntan por "lo que es" el populismo, pretendiendo así dar una definición general y aplicable a múltiples casos. Su modus operandi consiste en aislar ciertas características que aparecen como la naturaleza intrínseca del fenómeno. Sostienen que se debe entender como un "tipo ideal" o como un "parecido de familia", que indica de manera gradual si se está o no ante una situación populista (Canovan, 1981; Viguera, 1993; Roberts, 1995). El caso es que los que buscan la generalidad no dicen cuál es el principio unificador que hace que la diversidad de fenómenos considerados populistas se refieran a lo mismo (Laclau, 2009, p. 19). Por ir tras lo general caen en una abstracción, llena de notas dispersas, que es incongruente con los casos concretos; al final, cualquier cosa termina siendo populista.

No obstante, nuevas herramientas de análisis permiten pensar en la posibilidad de transitar caminos alternativos para lograr una mejor definición. Desde la publicación de La razón populista (2005), los aportes teóricos del filósofo argentino Ernesto Laclau, han permitido pensar en una nueva perspectiva ubicada más allá del paradigma positivista imperante en la ciencia política. De acuerdo a Laclau el populismo es una dicotomización del espacio social, delineada por cadenas de equivalencia entre demandas, que terminan por hegemonizarse a través de un significante vacío, cuyo nombre (pero no concepto) es el de "pueblo" (Laclau, 2009, p. 96). Esta propuesta resulta ser un gran paso en el debate porque: 1. permite dejar atrás el problema de las definiciones del populismo que se hacen identificándolo con una ideología (así se pueden abarcar más casos), 2. No es necesario designarle algún lugar o tiempo específico al populismo dentro de lo

resolver el problema satisfactoriamente no significa la inexistencia del problema, sino la obligación de explorar caminos alternativos que no pretenden dar una única respuesta definitiva, solamente postular la existencia de otros caminos, pese a que el interrogante se mantenga abierto. La importancia de este problema es que señala los límites de la teoría política moderna. Es desde esta perspectiva que se ha asumido esta investigación. 
social, puesto que su aparición puede darse en cualquier lugar/momento como articulación de demandas particulares (en razón de su carácter contingente) y 3. Proporciona un criterio claro para diferenciar al populismo de otras manifestaciones políticas a partir de una perspectiva (cuasi)trascendental, que permite preguntarse por las condiciones de aparición del populismo, dejando así de lado cualquier intento por determinar de manera atemporal y abstracta al fenómeno.

Por supuesto, no se trata del fin del problema. Más allá del gran aporte que representa la teoría de Laclau, varios autores han manifestado una serie de críticas ${ }^{3}$. Lo que tienen en común estos cuestionamientos es sostener que el populismo, según la concepción posestructuralista de Laclau, es una "hipóstasis", una "abstracción", otra "formalidad" más de una realidad concreta que exige análisis específicos. El pensador argentino cae en un "estiramiento conceptual" en el que cualquier cosa puede llegar a ser populista: "Esta definición de populismo parece tan general que casi cualquier movimiento o demanda política contemporánea puede ser caratulada de populista" (Barros, 2006, p. 68). Ligada a esta crítica existe otra: la identificación por parte de Laclau entre el populismo y la lógica política tout court:

[...] la noción de populismo pierde toda especificidad si se supone que el término designa no solo una forma específica de movilización política sino la acción política como tal. Y eso podría conducir enseguida a la pregunta: ipara qué, entonces, llamarlo populismo y no simplemente «política»? (Marchart, 2006, p. 41).

Con el propósito de llegar a una definición del populismo que evite los problemas del pasado, es necesario reproblematizar el planteamiento de Laclau, al igual que señalar los vacíos que pueden encontrarse en las soluciones que se han intentado proponer ante las críticas (Barros, 2006; Muñoz, 2006; Arditi, 2010). Siguiendo este camino es posible configurar un concepto de populismo que solvente el problema de la falta de especificidad señalada. En este sentido, la apuesta por entender la política como desacuerdo del filósofo francés Jacques Rancière resulta ser el elemento complementario indispensable. De todas maneras, este camino es susceptible a las críticas. Es por eso que se propone que el populismo posee un carácter eminentemente democrático, y que en consecuencia, se trata de una inclusión radical de aquellos miembros no contados por la comunidad.

Para lograr justificar estas afirmaciones, se seguirá la siguiente hoja de ruta: primero, expondremos los presupuestos filosóficos de la concepción de populismo de Ernesto Laclau, los problemas teóricos en medio de los que surge,

\footnotetext{
3 Son varios los que critican la apuesta de Laclau. Las más destacadas son las siguientes: Barros (2006, 2009), Arditi (2004, 2009, 2010), Aboy Carlés (2005), Retamozzo (2009), Muñoz (2006), Burdman (2009), Zîzêk (2006), Melo (2011) y Stavrakakis (2004).
} 
y asimismo, la dinámica conceptual que fundamenta su postura. En un segundo momento, y tras señalar los vacíos que puede llegar a tener esta propuesta, nos ubicamos en la obra del filósofo francés Jacques Rancière, quien permite entender la política como una práctica de inclusión radical. De esta manera, conectamos la postura de Laclau con la de Rancière, explicitando los puntos de encuentro y desencuentro entre ambos autores, y buscando dar respuesta a las críticas que se le plantean al primero. Paso seguido, y como continuación de lo anterior, señalamos los posibles problemas que tiene de todas formas una interpretación como la que se ofrece; así establecemos, finalmente, que el populismo es un fenómeno democrático y además un proceso de inclusión radical. Esta definición pretende ser una superación de los problemas de abstracción y excesiva especificidad que han sido rasgos distintivos de las investigaciones realizadas alrededor del concepto de populismo.

\section{Laclau: la ontología del populismo}

Los trabajos en torno al populismo, y que han tenido como contexto específico la situación latinoamericana, han atravesado tres grandes etapas: a. populismo clásico (1940-1980), b. neopopulismo (1990-2000) y c. populismo democratizador (2000-2013)4. Inspirados en los análisis funcionalistas, los primeros acercamientos (Germani, 1965) que tenían como referencia la figuras de Perón y Vargas, fallaban en razón de sus supuestos teleológicos, incapaces de brindar una teoría ubicua e indeterminada, en lo referente a ideologías y políticas económicas (Vilas, 1988). Posteriormente, el surgimiento de los denominados neopopulismos por los años 80's y 90's (principalmente, el de Fujimori), obligaron a un ensanchamiento de la definición, debido a las políticas neoliberales adoptadas por este tipo de liderazgos (que iban en contravía de las políticas de sustitución de importaciones de los populismos clásicos), cayendo así en el problema de una ambigüedad en lo referente al principio de unificación de tan dispersas características (Roberts, 1995). El concepto sufrió en este punto de un "estiramiento" (Vilas, 2004, p. 20). Más cercana en el tiempo, aparece la tesis de que el populismo puede llegar a convertirse en un fenómeno democratizador (Canovan, 1999) en razón de la movilización de las clases populares (especialmente en América Latina) previamente coaptadas por el clientelismo o por élites que las instrumentalizaban en aras de la legitimidad.

\footnotetext{
4 Varias taxonomías se han propuesto para dividir los modos y objetos de investigación en torno al populismo. Drake (1978) considera que el estado del arte se puede revisar a partir de las categorías "temprano", "clásico" y "tardío", a partir de un criterio que se apoya en las características diferenciales del fenómeno a través del tiempo. Para Canovan (1981) los estudios pueden clasificarse como "agrarios" y "urbanos". Para Panizza (2009), las definiciones pueden estudiarse según el principio metodológico que se privilegie: "empírico", "histórico", "Crítico". Y para Weyland (2001) la mejor clasificación es la que se refiere a las estrategias conceptuales utilizadas: "acumulativas", "aditivas" o de "redefinición".
} 
Laclau comparte la perspectiva democratizadora, aunque plantea una corrección en el enfoque adoptado: se deben examinar los elementos discursivos que entran en juego en el momento en que surge un movimiento que puede ser considerado como populista con el propósito de poder determinar las condiciones que permiten su emergencia ${ }^{5}$. El pensador argentino plantea también la necesidad de entender al fenómeno según perspectivas no esencialistas, que describan el proceso de constitución de las identidades colectivas, pero sin caer en indeterminaciones como la ofrecida por conceptualizaciones que utilizan los "parecidos de familia" de Wittgenstein ${ }^{6}$ sin un sustento metodológico. Pero Laclau parte de una perspectiva ontológica que se pregunta por las condiciones de aparición del populismo, lo que le permite plantear una explicación ubicua y vacía de contenido ideológico. Sin embargo, no deja de señalar el modo en que lo social termina por configurarse a partir de la dinámica empírica de la política (Marchart, 2006, p. 50).

Pero el proyecto de Laclau no se detiene acá, implica una serie de tesis mucho más arriesgadas. En La razón populista (2005) conceptualiza al populismo como el fenómeno político tout court: "Invirtiendo el papel que generalmente se le asigna al populismo, este pasa, de ser un fenómeno aberrante e irracional en los márgenes de lo social, a ser el rasgo central y la racionalidad específica de lo político" (Marchart, 2006, p. 40). El gran objetivo del pensador argentino es llevar a un punto mucho más alto su anterior investigación en torno al populismo (1976), enriqueciéndolo con perspectivas postestructuralistas que desde Hegemonía y estrategia socialista (1985) han venido siendo determinantes en su obra, para lograr así no sólo desmitificarlo, sino también ubicarlo como la anatomía misma de lo político.

Para alcanzar este objetivo comienza por señalar la insatisfacción que le han provocado dos grandes supuestos metodológicos de la tradición política moderna: a. tomar como unidad de análisis al grupo y b. pretender definir al populismo sin percatarse de la necesidad de una explicación ontológica, es decir, sin describir las condiciones de posibilidad que permiten la constitución

\footnotetext{
${ }^{5}$ Lo discursivo tiene en Laclau el carácter de una ontología social. Para él lo que está en juego en la política es el establecimiento de significados por medio de las relaciones de poder, que terminan por constituir la subjetividad y el orden reconocido. Lo discursivo incluye lo extralingüístico, en la medida en que toda práctica social posee significados que son dados a través de una decisión política, por medio de un antagonismo que se resuelve en la exclusión de otros significados. Para profundizar en la Teoría del discurso de Laclau y Mouffe, en el capítulo III de Hegemonía y estrategia socialista (2009) se encuentra la base de los desarrollos que vendrán después por parte del propio Laclau.

6 "Quizás se podría sostener que lo que Canovan nos brinda no es una tipología [...], sino más bien un mapa de la dispersión lingüística que ha dominado los usos del término populismo. Los parecidos de familia de Wittgenstein pareciera, hasta cierto punto, apuntar en esta dirección [...] Pero aun si este fuera el caso, la lógica que domina esta dispersión requiere una mayor precisión [...]" (Laclau, 2009, p. 19).
} 
del sujeto popular: "Nuestro enfoque parte de una insatisfacción básica con las perspectivas sociológicas que [...] consideran al grupo como la unidad básica de análisis social[...]" (Laclau, 2009, p. 9), "[...] el impasse que experimenta la teoría política en relación con el populismo está lejos de ser casual, ya que encuentra su raíz en la limitación de las herramientas ontológicas actualmente disponibles para el análisis político" (16). Esta última parte de la cita explicita el método del autor: ubicar como centro de análisis a las demandas sociales, que son justamente las que constituyen a los sujetos. La unidad mínima de análisis serán las demandas.

De acuerdo a críticas como la de José Luis Villacañas (2010) es necesario explicitar cómo deben entenderse las "demandas" de Laclau. Según este cuestionamiento, Laclau asume a primera vista una postura liberal, porque presupone la racionalidad economicista de satisfacción de necesidades: si la demanda es satisfecha por la institucionalidad la producción de una subjetividad popular no puede existir. Pero si la demanda aparece en un campo de negatividad, esto es, no puede ser satisfecha, el sujeto popular sale a la luz. Al no ser satisfecha la demanda por las vías procedimentales o por vías informales incluso (una relación clientelar puede satisfacerla), comienza a surgir una insatisfacción que se va convirtiendo en una oposición, y así comienza a germinar el movimiento populista.

Ante esto, se pueden hacer dos aclaraciones. La primera tiene que ver con el doble sentido de la palabra inglesa demand que puede ser entendida como "petición" y como "reivindicación". El carácter de reivindicación lleva a considerar que la demanda no surge de un sujeto constituido e idéntico a sí mismo, sino que la demanda es el punto de partida en la constitución de una nueva identidad que no existe mientras no se convierta en reivindicación. La dinámica de lo político, plantea Laclau, implica la constitución de una nueva identificación durante el propio proceso, que tiene como uno de sus momentos la aparición de la reivindicación. Esto se conecta con la segunda aclaración que tiene que ver con la herencia lacaniana de Laclau. Daniel Gutiérrez Vera (2011) ha señalado la pertinencia de distinguir entre identidad e identificaciones. Partiendo de un sujeto escindido en razón de la totalidad imposible del deseo, se postula la necesidad de establecer identificaciones parciales que nunca apunta al cierre, sino solo a la sutura contingente por medio del antagonismo político. De modo que si tiene presente la raíz lacaniana en la concepción de Laclau, se puede comprender la postura antiesencialista de la subjetividad del pensador argentino, y por ende, la renuncia radical a postular contradictoriamente un sujeto liberal ${ }^{7}$.

\footnotetext{
En este punto hay una inconsistencia en Laclau que se refiere a su inconsistencia con respecto a no ser capaz de asumir radicalmente la teoría de la subjetividad psicoanalítica. Pese a que en diversos lugares a reconocido su deuda con el psicoanálisis en este punto de las demandas, Laclau, parece caer en un contrasentido al afirmar una lógica de las necesidades. Considero que la dificultad radica en la necesidad de Laclau de postular de entrada la negatividad social, sin postular al mismo tiempo una antropología, probablemente porque esto lo hacía pensar en un nuevo esencialismo, como ocurrió
} 
Teniendo en mente el sentido de las demandas en Laclau, podemos continuar con su argumentación:

\begin{abstract}
Si la demanda es satisfecha, allí termina el problema; pero si no lo es, la gente puede comenzar a percibir que los vecinos tienen otras demandas igualmente insatisfechas. Si la situación permanece igual por un determinado tiempo, habrá una acumulación de demandas insatisfechas y una creciente incapacidad del sistema institucional para absorberlas de un modo diferencial y esto establece entre ellas una relación equivalencial (2009, p. 98).
\end{abstract}

La relación equivalencial se produce cuando diversas demandas insatisfechas comienzan a unirse por un lazo de solidaridad que se solidifica con respecto a aquello que las niega. Se crea la unidad gracias al antagonismo con respecto al "lugar del poder" que no responde a la pluralidad de demandas. Lo que no quiere decir que el antagonismo solo aparezca en el momento de la negación, sino que es reactivado y extraído de su forma institucional sedimentada. Por su lado, la relación diferencial responde a una dinámica de respuesta individual: no se pretende la vinculación con otro tipo de demandas de lo social.

En este punto cabe preguntarse por la manera en que la particularidad de las demandas en una relación equivalencial alcanza la universalidad, es decir, cómo de una serie de demandas particulares — probablemente diferentes entre síse pasa a una demanda que conjuga el contenido de las demás; se trata de un proceso que es justamente la clave de una operación que termina por construir al sujeto del populismo, es decir, al pueblo. En una primera instancia, Laclau, nos dice que se trata de una "unidad simbólica", esto partiendo de su concepción del discurso que trasciende lo meramente lingüístico y es constitutivo de todos los significados del espacio social: "[las demandas] sólo pueden consolidarse cuando se avanza unos pasos, tanto mediante la expansión de las cadenas equivalenciales como mediante su unificación simbólica" (2009, p. 99). La unificación la explica Laclau a través del concepto de significante vacío heredado del estructuralismo lingüístico y el psicoanálisis lacaniano. Lo que es indispensable resaltar en este punto —dejando a un lado un gran número de consideraciones- es que la unificación surge por medio de un "vaciamiento" del significante que consiste en la capacidad de representar una mayor cantidad de particularidades sin restringir el contenido específico de las demandas. Un significante debe estar unido a un significado — afirmaba la lingüística estructural_; sin embargo, puede ocurrir un rompimiento en la medida que el significante se ubique al exterior del sistema diferencial de significados como consecuencia de la indeterminación que surge dentro del propio sistema. Debido a que la identificación del sistema debe darse

con la Teoría Crítica (Honneth, 2009, p. 28ss). Si se planteara el trabajo de reconstruir una antropología en la obra de Laclau, se haría mucho más evidente su fidelidad con los presupuestos postestructuralistas y psicoanalíticos (Laclau y Mouffe, 2009, p. 11).

Revista Filosofía UIS, vol. 17, $n .^{\circ} 1$, enero-junio de 2018 
por medio de una relación diferencial, es necesario que el sistema posea un "exterior constitutivo" que le otorgue su identidad. Como el sistema se configura por medio de sus elementos internos, el propio sistema debe tener un límite que no puede ser significado (de lo contrario sería interior al sistema). Este límite debe ser la subversión del propio sistema, es decir, debe ser la imposibilidad del proceso de significación:

De tal modo, nos encontramos en la situación paradójica de que aquello que constituye la condición de posibilidad de un sistema significativo — sus límites- es también aquello que constituye su condición de imposibilidad —un bloqueo en la expansión continua del proceso de significación (Laclau, 1996, p. 71).

Este límite es el significado vacío, la imposibilidad del sistema de significarse a sí mismo, pero la posibilidad de existencia del propio sistema. Es la ruptura de la lógica diferencial, porque se suspende la lógica de unir los significados por medio de diferencias en aras de alcanzar una equivalencia significante. Se deja a un lado el carácter diferencial por medio de un vaciamiento del significado. Es en este sentido que el significante vacío es: "[...] el sujeto político global que reúne una pluralidad de demandas sociales" (Laclau, 2009, p. 150). "El argumento que he venido desarrollando es que, en este punto, existe la posibilidad de que una diferencia sin dejar de ser particular, asuma la representación de una totalidad inconmensurable" (95). El significante vacío es una demanda entre las demás, su particularidad consiste en permitir fijar la identidad de las otras a través del vaciamiento de su significado ${ }^{8}$, lo que le permite ampliar su campo de representación. Para que diversas demandas puedan llegar a articularse es necesario que sean equivalentes con respecto a un elemento de negatividad y que encuentren un significante lo suficientemente vacío que las represente.

Hay una serie de precisiones que se abordan a lo largo de La razón populista, como el problema de la representación liberal, las cadenas muy extensas de demandas, la heterogeneidad (lo supernumerario que no puede recibir ni un nombre, ni un concepto), la nominación, que no se van a abordar en esta síntesis,

\footnotetext{
${ }_{8}^{8}$ Para Laclau, un significante sin significado sólo sería mero ruido, por lo tanto, cree que el significado de este significante es otorgado a través de la necesidad de ponerle límites al sistema; así, puede ocurrir que un significante que se encuentre por fuera del sistema, sea al mismo tiempo el que le brinda la identidad al propio sistema... (es un "exterior constitutivo"). En una relación equivalencial las demandas poseen dos rostros: el de su similitud con otras demandas (dos vecinos puede compartir la insatisfacción ante una situación de inseguridad en el barrio) y de su absoluta diferencia (para un vecino lo importante es el transporte, pero para el otro la tranquilidad que produce la ausencia del ruido de los buses). Sin dejar de afirmar su radical diferencia, las demandas equivalenciales resaltan su lado homogéneo, el cual es construido a partir de la negatividad que brinda el "enemigo". Esta negación comunitaria de un "otro" es lo que le proporciona el vaciamiento al significante. Para mayor claridad y extensión, se recomienda el texto de Laclau (1996). "¿Por qué los significantes vacíos son importantes para la política?"
} 
por razones de espacio, y también porque se trata de elementos que no se involucran necesariamente con nuestra propuesta. Lo que vale la pena resaltar es la forma en que Laclau aborda el estudio del populismo ubicándose en una posición neutra en términos ideológicos y económicos. De esta forma, los contenidos que pueda adquirir el populismo circunstancialmente no son determinantes para ser tal. En la argumentación de Laclau pueden ser igualmente populistas el peronismo, el chavismo y el fascismo: "Por lo tanto, el populismo, en un sentido similar al que hemos descripto en este libro, no es una constelación fija, sino una serie de recursos discursivos que pueden ser utilizados de modos muy diferentes" (2009, p. 220).

Ahora bien, tras la publicación de La razón populista y la defensa de tesis radicales (el populismo es igual a lo político), aparecieron diversas críticas. En primera instancia las críticas se refirieron a la identificación entre el populismo y lo político, ya que aceptar esta tesis supone la incapacidad de diferenciar fenómenos con condiciones de aparición distintas. Relacionada con esta crítica, aparece una segunda que menciona la falta de especificidad del populismo, que lo convierte en una hipóstasis imposible de precisar para el análisis de los casos concretos: ¿cómo sabemos que tal cosa es populismo y que tal otra no? De esto se sigue, que no permite diferenciar al populismo de cualquier otro tipo de articulación de demandas. Uno de sus discípulos ha sintetizado esta doble acusación:

Si el populismo se identifica con lo político, y si cualquier significante se puede convertir potencialmente en el punto de nodal de un discurso populista, ¿cómo podemos distinguir conceptualmente entre un discurso equivalencial articulado alrededor del pueblo y cualquier otro discurso equivalencial? [...] ¿Qué es lo específico del populismo? [Traducción propia] (Stavrakakis, 2004, p. 263).

Surge entonces la pregunta: ¿Puede tener especificidad el concepto de populismo ofrecido por Laclau? Si se realiza una lectura complementaria no solo se obtiene una explicación ontológica (y en ese sentido ubicua, contingente y vacía ideológicamente), sino también la especificidad del populismo (puede adquirir un contenido óntico).

\section{Rancière: la especificidad del populismo a través de la inclusión radical}

Pretendemos, entonces, añadir un elemento teórico que, sin desvirtuar las intenciones y los presupuestos del populismo ontológico-discursivo, pueda dar respuesta a su señalada falta de especificidad. Nos referimos al "desacuerdo" como rasgo constitutivo de la política, defendida por el filósofo francés Jacques Rancière. La forma conflictiva y disruptiva desde la que Rancière comprende la política, la comunidad y la subjetividad Ilena el hueco de la especificidad que aparece en la propuesta de Laclau (Muñoz, 2004; Barros, 2009). 
Al final de La razón populista, Laclau, dedica unas cuantas páginas a dialogar con aquellos pensadores que se interesan por problemas similares a los que él viene trabajando desde los días de Política e ideología en la teoría marxista (1976). Entre ellos, aquél por quien demuestra una mayor admiración es Jacques Rancière, pues, considera que su noción de "pueblo" está en total consonancia con la suya. Lo que destaca de la obra de Rancière como coincidente con su planteamiento es lo siguiente:

a. El carácter fallido de lo social que sirve de trasfondo a toda constitución hegemónica:

Lo que hemos caracterizado como el desnivel inherente a la operación hegemónica, Rancière lo conceptualiza como un incontable que trastorna el principio mismo de la contabilización y, de esa manera, hace posible el surgimiento de lo político como un conjunto de operaciones que tienen lugar en torno a esta imposibilidad constitutiva (Laclau, 2009, p. 305).

b. La vacuidad en el surgimiento de una articulación populista, que es coherente con el conflicto constituyente de la política: "En segundo lugar, la noción de Rancière de una clase que no es una clase, que tiene como determinación particular algo del carácter de una exclusión universal $[. .$.$] no está lejos de lo que hemos denominado "vacuidad»"$ (Laclau, 2009, p. 305).

c. El pueblo como sujeto que irrumpe en la comunidad (o en lo social), resaltando su imposible plenitud:

El pueblo es, tanto para él como para nosotros, el protagonista central de la política, y la política es lo que impide que lo social cristalice en un sociedad plena, una entidad definida por sus propias distinciones y funciones precisas" (2009, p. 309).

De la misma manera existen divergencias entre los dos pensadores: a. Laclau supone una ontología que para Rancière es innecesaria a la hora de proponer una teoría de la emancipación (Rancière, 2003, p. 8), b. para Laclau, Rancière comete un error en razón de su confianza extrema en el contenido democratizante de las disrupciones políticas, desconociendo la posibilidad de que la disrupción surja como intención de algún grupo totalitario: "Pienso que Rancière identifica demasiado la posibilidad de la política con la posibilidad de una política emancipatoria, sin tomar en cuenta otras alternativas" (2009, p. 306). Precisamente, estas diferencias son las que nos permiten establecer la relación complementaria: Laclau brinda una concepción que explica el surgimiento de las identidades políticas en relación con el antagonismo que se establece entre los miembros de la comunidad consolidándose con la constitución del sujeto político, lo cual se complementa con la especificidad que brinda Rancière al revelarnos el contenido de este proceso (inclusión radical). En términos del pensamiento posfundacional (Marchart, 2009), podemos afirmar que el plano ontológico en el 
que se ubica Laclau carece de una especificidad, que es dada por el planteamiento óntico brindado por Rancière. Este punto de encuentro es el que permite relacionar las dos concepciones en aras de realizar la lectura complementaria. Revisemos brevemente la propuesta de Rancière.

El desacuerdo (1995) comienza con una puesta en cuestión de la aparente relación necesaria entre filosofía y política. Desde Platón y Aristóteles se ha pensado que la filosofía abre nuevos caminos cuando la política se estanca en las meras apariencias. Esto se traduce en la inclinación natural de la política por valerse de la filosofía para establecer fundamentos que le permitan elaborar un orden teleológico de la comunidad. Una de las maneras en que se ha expresado este ordenamiento de las partes de la comunidad ha sido por medio de una distinción entre los sujetos que usan el lenguaje legítimamente y los que no. Para Aristóteles sólo el hombre posee la palabra (lógos), mientras que los demás seres vivos sólo tienen acceso al ruido (phoné); los primeros reconocen lo justo y lo injusto, mientras los segundos sólo pueden expresar dolor y placer. Siguiendo su idea de la partición del alma según las prácticas humanas, y de acuerdo al principio que distingue entre las formas de acceder a lo sensible (Aristóteles, 2010, 1253a918), el ejercicio de la política, entonces, es lo que compete a la parte racional, y por ende, es competencia de los detentadores del lógos. La política solo puede darse entre aquellos seres que se apoyan en la palabra (Rancière, 1996, p. 13).

Cuando se cuestiona el principio de la cuenta errónea de asignación de los lugares predeterminados en la comunidad surge el desacuerdo. El desacuerdo es el efecto del "daño" (tort) que sufren aquellos que no tienen acceso a la palabra, que no se cuentan como partes de la comunidad. Este daño surge a raíz de la falsa cuenta de la filosofía: "La política existe cuando el orden natural de la dominación es interrumpido por la institución de una parte de los que no tienen parte" (Rancière, 1996, p. 25). La política surge en el momento en que la parte no contada reclama ser el todo, cuando la plebs aspira a ser el populus. ¿Pero cómo es que puede darse este reclamo? ¿Qué propiedad posee la parte no contada que le permite exigir ser el todo de la comunidad? La irrupción de los que no tienen parte en la comunidad se debe a la comprobación del principio mismo que conforma a la comunidad, esto es, cuando se actualiza la libertad. La única cualidad de quienes no son contados como partes (el Demos) es la libertad, y es a partir de su puesta en práctica que exigen ser el todo:

Puesto que la libertad — que es simplemente la cualidad de quienes no tienen ninguna otra: ni mérito, ni riqueza - se cuenta al mismo tiempo como la virtud común. Permite al Demos identificarse por homonimia con el todo de la comunidad (Rancière, 1996, p. 22). 
De esta forma "el Demos se atribuye como parte propia la igualdad que pertenece a todos los ciudadanos" (22). Acá entra en juego otro elemento central en el proceso de subjetivación política que nos ofrece Rancière, se trata de la policía. Policía es la instancia mediante la cual se asignan los lugares de aparición de lo que se habla, se piensa, se escucha; o en otras palabras, la policía es uno de los dos modos a través de los cuales se realiza la "partición de lo sensible". Por lo tanto, se opone a la política en el sentido de que su pretensión es la de mantener y legitimar la partición comunitaria, mientras la política se define por su carácter disruptivo (Ranciére, 1996, p. 43). Esta oposición entre "política" y "policía" constituye el campo de los procesos de subjetivación. Pero esto hay que entenderlo adecuadamente: no se trata de dos subjetividades separadas, sino de una indistinción entre la lógica policial y la política que provoca el surgimiento del pueblo. De esta manera, toda transformación en la distribución de las partes de la vida comunitaria conlleva el desprendimiento del lugar natural que ocupan por medio de un proceso de desidentificación. La subjetivación se da en un "entremedio": a partir de los modos de hacer y decir de la policía y a partir de la subversión de esos mismos modos que supone la política. Una subjetivación es la creación de un nuevo campo de la experiencia que no se encontraba antes y que transforma las condiciones preestablecidas del aparecer y el sentir. Del encuentro de la lógica policial con la de la política-igualdad, surgen nuevas subjetividades que reformulan los modos de representación imperantes de una manera inédita:

Hay subjetivación, en general, cuando un nombre de sujeto y una forma de predicación instituyen una comunidad inédita entre unos términos y dibujan, de este modo, una esfera de experiencia inédita que no puede incluirse en los repartos existentes sin hacer explotar las reglas de inclusión y los modos de visibilidad que los ordenan (Rancière, 2011, p. 159).

En síntesis: desde la perspectiva de Rancière la política es un asunto conflictivo, que se basa en la verificación de la igualdad por parte de las partes que no cuentan como partes. Surge del litigio inherente al todo de la comunidad, cuyo impulso principal es la posibilidad de que la parte "dañada" asuma la representación del todo: la plebs se convierte en el pueblo (populus). Esta irrupción ocurre por medio de un proceso de subjetivación que arranca a los sujetos de los lugares originales demarcados y regulados por la policía.

Siguiendo a Sebastián Barros en este punto, podemos establecer la relación complementaria con el ánimo de otorgarle especificidad a la concepción de Laclau:

A partir de la lectura de Rancière podemos contribuir a una definición de populismo planteando, en primer lugar, que la figura del pueblo remite a una politización de ciertas demandas que hasta ese momento no eran representadas en la práctica hegemónica vigente sino como partes que no 
contaban. Por otra parte, y en segundo lugar, esa inclusión genera que esa ahora-parte reclame para sí la representación de la totalidad comunitaria en nombre del daño sufrido por la institucionalidad vigente (Barros, 2009, p. 21).

La crítica por falta de especificidad es desvirtuada de acuerdo a la consideración de la propuesta de Ranciére, pues, si se aducía que con la teoría de Laclau cualquier manifestación política podía ser populista, ahora sabemos que no es así: el populismo será la práctica política en la que los incontados irrumpen en el orden representativo por medio de una subjetivación que transforma lo común Podemos establecer en este punto que la falta de especificidad señalada en la propuesta de Laclau tiene su origen en la ubicación por parte del autor argentino de las demandas dentro de un espacio de reconocimiento que toma toda demanda como objeto claro de representación, con lo cual cualquier demanda puede adquirir un carácter populista (Barros, 2010, p. 123). Ahora se puede plantear que solo es posible considerar un fenómeno como populista tras la irrupción de las demandas que no hacían parte del modo de reconocimiento preconstituido: "Cuando una práctica incluya el principio del pueblo como lo irrepresentado, haga que aquellos que no tienen por qué hablar, hablen, y que aquellos que no tienen por qué tomar parte, tomen parte recién allí podremos hablar de populismo" (Barros, 2009, p. 21). De esta manera, el populismo es un rompimiento del espacio institucional en el que los no representados son incluidos de manera radical a través de la constitución de una nueva subjetividad (el pueblo) política (Barros, 2006, p. 72).

\section{Nuevos cuestionamientos, nuevas alternativas:}

Hasta acá tenemos una respuesta a la crítica por falta de especificidad, que ya han planteado algunos de los discípulos de Laclau, como Sebastián Barros y Benjamín Arditi. Sin embargo, esta respuesta aún no ofrece una solución satisfactoria ante los dos cuestionamientos. En primer lugar, la identificación entre populismo y lo político se mantiene, porque justamente la concepción de Rancière es un modo de entender la dinámica de lo político ${ }^{9}$. En ese caso, definir al populismo a partir de lo que caracteriza a lo político, solo plantea la necesidad de eliminar alguno de los dos conceptos. En caso de eliminar el concepto de lo político, sustituyéndolo por el de populismo, nos dejaría con el problema de tener que negar la existencia de otro tipo de formas de constitución de lo social, como puede ser el institucional.

\footnotetext{
9 "¿Qué es lo político? se nos pregunta. Responderé brevemente: lo político es el encuentro de dos procesos heterogéneos. El primero es el del gobierno [policía]. [...] El segundo es el de la igualdad [...] Lo político será el terreno del encuentro entre la política y la policía en el tratamiento de un daño" (Rancière, 2006, pp. 17-18).
} 
De acuerdo a lo anterior, plantear una alternativa para el problema de la identificación que realiza Laclau, debe pasar por lo que señala Benjamin Arditi:

Esta es la razón por la que se puede decir que el populismo es una especie del género [lo político], la especie cuestiona el orden existente con el propósito de construir otro orden (pp. 156-167). Este género tiene por lo menos, una especie más, el discurso institucionalista, cuya esencia es mantener el status quo (Arditi, 2009, p. 492).

Desde la perspectiva de formación de conceptos clásica (Copi y Cohen, 2005, p. 196), el populismo sería una especie —así como la institucionalidad_ perteneciente al género "lo político". De esta manera, podemos diferenciar entre el populismo y lo político, con lo cual no tenemos el problema de la superposición de términos. El populismo se relacionará con lo político como uno de sus modos de manifestación concreta. Aparentemente Laclau estaría de acuerdo con esta postura:

Nuestro intento no ha sido encontrar el verdadero referente del populismo, sino hacer lo opuesto: mostrar que el populismo no tiene ninguna unidad referencial porque no está atribuido a un fenómeno delimitable, sino a una lógica social cuyos efectos atraviesan una variedad de fenómenos. El populismo es, simplemente, un modo de construir lo político (2009, p. 11).

Tenemos entonces que populismo y lo político no son lo mismo: lo político es la lógica general que describe la articulación de toda práctica política; el populismo es una de las maneras a través de las cuales ocurre esta articulación, la otra es la institucionalidad liberal. Pasando a la otra crítica, la que señala la falta de especificidad del populismo, tenemos que la solución complementaria ofrecida por algunos autores (Barros, 2009; Arditi, 2008) parece albergar un inconveniente realmente importante. Más arriba mencionábamos las reservas que tenía Laclau hacia la confianza de Rancière en el contenido reivindicativo emancipatorio de la parte no contada: "Pienso que Rancière identifica demasiado la posibilidad de la política con la posibilidad de una política emancipatoria, sin tomar en cuenta otras alternativas" (2009, p. 306). Es posible que la parte de los sin parte pretenda convertirse en el todo de la comunidad a partir de exigencias autoritarias, neonazis, xenófobas, etc., y así entonces el proceso de subjetivación, puede pasar a ser la consolidación de un espacio común antidemocrático. Es concebible desde este presupuesto que los grupos anti-refugiados del centro de Europa consoliden un programa xenófobo como efecto de su irrupción en la comunidad en tanto parte no contada, en un contexto de acogimiento a los desplazados por la violencia del Estado Islámico. Esto permite pensar que la especificidad que se le pretendía otorgar al populismo queda entredicha; debería especificarse todavía más con el propósito de señalar la necesidad de que la inclusión radical sea realmente emancipatoria. ¿Cuál podría ser este otro elemento que permita determinar esta especificidad? 
Acá la influyente idea de Claude Lefort (1988) en torno a la revolución democrática es central. Tal y como la piensa Lefort, la democracia es el acontecimiento histórico en el que el lugar del poder debe entenderse como perpetuamente vacío, en el que presenciamos la "disolución de los marcadores de certeza" modernos. La democracia como proceso histórico se convierte en la condición ineludible de toda práctica política, porque se trata de un cambio simbólico ineludible; al rey le han cortado la cabeza perpetuamente (Marchart, 2006, p. 51). En este sentido, el modo de legitimación del orden social deja de pertenecer a un orden trascendente, para instalarse definitivamente en la figura del pueblo. Pero al mismo tiempo, el sujeto de la política, en tanto detentador de la soberanía, resulta ser el mismo pueblo. Se trataría de una experiencia histórica en la que se instala una soberanía sin soberano, en razón de la vacuidad permanente que posee el lugar del poder:

Se comprende que el pueblo se verá dividido constitutivamente: por un lado tiene que asumir la función clásica de la soberanía, pero por otro esa función será más que precaria, pues el pueblo no puede recurrir a ninguna base trascendental de legitimación (Marchart, 2006, pp. 52-53).

Podemos en este punto afirmar que la construcción del pueblo, rasgo característico del populismo para Laclau, y concreción del proceso de subjetivación política para Rancière, no podrá adquirir un carácter no-democrático, en la medida que el pueblo es un soberano contingente que no posee ningún tipo de atributo trascendente que le permita alcanzar una legitimidad autoritaria. Cuando se construya el pueblo este deberá "fundamentarse" sobre la imposibilidad de concretar un orden social de acuerdo a marcos autoritarios que no se expongan al cuestionamiento de sus propios principios. Así, el populismo como forma de construir al pueblo, no podrá derivar en un tipo de identificación autoritaria o trascendente, en razón del carácter irreversible de la revolución democrática. El populismo adquiere mayor especificidad al considerarse entonces como expresión de la democracia. Aquello que no reivindique la voluntad popular y la exigencia de igualdad no podrá ser considerado populista.

\section{Conclusión}

Tenemos entonces que el populismo es una especie del género "lo político", una especie en la cual la institución de la sociedad se da a través de cadenas de equivalencia, antagonismos sociales, significantes vacíos, que surgen de la irrupción de los incontados en el campo de la representación comunitaria por medio de la construcción del pueblo en el contexto histórico de la revolución democrática. La otra especie de este género (pueden haber más, por ejemplo, la dictadura) es la institucionalidad, la cual configura el orden social a partir de las formas y 
procedimientos de la política liberal, esto es, manteniendo el orden vigente. Se constituye así un concepto "jerarquizado", que se mueve entre la especificidad y la generalidad, que en primera instancia puede ser útil para consolidar una definición.

La alternativa que se ofrece, de acuerdo a la lectura complementaria entre Laclau y Rancière, no cae en los problemas ni de especificidad ni de generalidad, como ocurre con la mayoría de la literatura. En primer lugar, la especificidad viene dada por la idea de lo político como una irrupción de la parte no contada de la comunidad, que al incluirse en el espacio comunitario despliega un proceso de subjetivación que constituye al pueblo. Precisamente, el pueblo al ser el sujeto de la democracia, Ileva a postular al populismo como una práctica decididamente democrática al tratarse de la lógica misma a través de la cual se construye el pueblo: donde se constituya un pueblo, habrá un populismo y también aparecerá una democracia. Por otro lado, este concepto posee la virtud de que puede ser aplicado en distintos contextos en razón de que se encuentra elaborado según la lógica de las articulaciones que constituyen las identidades políticas, es decir, es una explicación ontológica acerca de la forma en que los sujetos y los colectivos son configurados por el ejercicio de la política (lo cual puede suceder donde quiera que haya política).

Hay que aclarar que son varios los prespuestos que se asumen acá, y que deberían especificarse más detalladamente para poder consolidar una propuesta más sólida. Claramente, se entiende la democracia como una manifestación social de carácter simbólico (no como una forma de gobierno o una norma política) que instituye un nuevo orden —o reparto de lo sensible, según Rancière- en el que las funciones y los lugares de la comunidad son cuestionados. Siendo así, Trump no sería considerado populista al reivindicar formas de socialización con claros componentes autoritarios y xenófobos. Sin importar que sea de derecha, Trump no validaría el proceso histórico-simbólico de la democracia, lo que impediría considerarlo como populista. Esta consecuencia, probablemente, tiene su origen en el carácter positivo que Laclau quiso resaltar del populismo, condicionado, seguramente, por su propia experiencia latinoamericana (Chávez, Correa, Morales).

Esto puede ocurrir porque, sin hacer un desplazamiento hacia un plano óntico, la democracia es considerada como un proceso histórico universal, lo que inevitablemente puede desencadenar ciertas críticas de tipo postcoloniales, o como en el caso de Trump, un cuestionamiento por desconocer la importancia del tipo de liderazgo, es decir, por desplazar el análisis hacia formas trascendentales abstractas que desconocen la realidad situada espacial y temporalmente. De todas maneras, se trata de una apuesta cuasi-normativa que puede seguir siendo explorada con el fin de recuperar el concepto de populismo de la dispersión conceptual que lo caracteriza actualmente, lo que seguramente ha surgido como 
consecuencia del empleo de metodologías positivistas incapaces de rastrear el devenir social que se expresa en una situación como la del populismo. Laclau ha permitido alejar algunos de los prejuicios clásicos, resta todavía contrastar el concepto con los fenómenos políticos del día a día.

\section{Referencias}

Aboy, C. G. (Noviembre de 2005). La democratización beligerante del populismo. VII Congreso Nacional de Ciencia Política, SAAP. Congreso llevado a cabo en Córdoba, Argentina.

Abts, K. \& Rummens, S. (2007). Populism versus Democracy. Political Studies, 55(2), 405-424.

Arditi, B. (2004). Populism as a Spectre of Democracy: A Response to Canovan. Political Studies, (52), 135-143.

Arditi, B. (2009). El populismo como espejo de la democracia. Buenos Aires: Fondo de Cultura Económica.

Arditi, B. (2010). Populism is Hegemony is Politics? The Theory of Populism by Ernesto Laclau. Constellations, 17(2), 488-497.

Aristóteles (2010). Metafísica. Madrid: Gredos.

Barros, S. (2006). Inclusión radical y conflicto en la constitución del pueblo populista. Confines, (2-3), 65-73.

Barros, S. (2009). Salir del fondo del escenario social: sobre la heterogeneidad y la especificidad del populismo. Pensamiento plural, 11-34.

Biglieri, P. y Perelló, G. (2007). En el nombre del pueblo. El populismo kirschnerista y el retorno del nacionalismo. San Martín: Universidad Nacional de San Martín.

Brenes, A. (2011). Estrategias conceptuales sobre populismo: un estado de la cuestión. Revista Derecho Electoral, (11), 1-22.

Burdman, J. (2009). Heterogeneidad, irrupción radical y mito en la génesis de las interpelaciones populistas durante la conformación del peronismo. Revista SAAP, 3(3), 616-634.

Canovan, M. (1981). Populism. New York: Hardcourt-Brace Jovanovic. 
Canovan, M. (1999). Trust The People, Populism and the Two Faces of Democracy. Political Studies, 47(1), 2-16.

Copi, I. y Cohen, C. (2005). Introducción a la lógica. México: Limusa.

De La Torre, C. (2005). Álvaro Uribe o el neopopulismo en Colombia. Medellín: La Carreta.

Drake, P. (1978). Socialism and Populism in Chile, 1932-1952. Chicago: University of Illinois Press.

Germani, G. (1965). Política y sociedad en una época de transición: de la sociedad tradicional a la sociedad de masas. Buenos Aires: Paidós.

Gutiérrez Vera, D. (2011). El populismo y sus avatares. Íconos, (40), 151-168.

Hermet, G. (2003). El populismo como concepto. Revista de Ciencia Política, 23(1), 5-18.

Honneth, A. (2009). Patologías de la razón. Madrid: Katz.

Laclau, E. (1985). Política e ideología en la teoría marxista. Buenos Aires: Siglo XX.

Laclau, E. (1993). The Blackwell Companion to Contemporary Political Thought. Australia: The Australian National University.

Laclau, E. (1993). Nuevas reflexiones sobre la revolución de nuestro tiempo. London: Verso.

Laclau, E. (1996). Emancipación y diferencia. Buenos Aires: Ariel.

Laclau, E. (2006). La deriva populista y la centroizquierda latinoamericana. Nueva Sociedad, (205), 56-61.

Laclau, E. (2009). La razón populista. Buenos Aires: Fondo de Cultura Económica.

Laclau, E. y Mouffe, C. (2009). Hegemonía y estrategia socialista. Buenos Aires: Fondo de Cultura Económica.

Lefort, C. (1988). Democracy and Political Theory. Minneapolis: University of Minnesota Press.

López, C. (2010). Y refundaron la patria. De cómo mafiosos y políticos reconfiguraron el Estado colombiano. Bogotá: Debate. 
Mackinnon, M. y Petrone, M. (1999). Los complejos de la Cenicienta. Populismo y neopopulismo en América Latina: el problema de la Cenicienta. Buenos Aires: Eudeba.

Marchart, O. (2009). El pensamiento político posfundacional. Buenos Aires: Fondo de Cultura Económica.

Melo, J. (2011). Hegemonía populista: ¿̇hay otra? Identidades, 1(1), 48-69.

Muñoz, M. A. (2006). Laclau y Rancière: Algunas coordenadas para la lectura de lo político. Andamios, 2(4), 119-144.

Olivera, G. (2005). Revisitando el síntoma del populismo. Metapolítica, 44(9), 51-58.

Panizza, F. (2009). El populismo como espejo de la democracia. México: Fondo de Cultura Económica.

Rancière, J. (1995). Democracia y post-democracia. Ideas y valores, (98-99), 23-40.

Rancière, J. (1996). El desacuerdo: filosofía y política. Buenos Aires: Nueva Visión.

Rancière, J. (2011). El tiempo de la igualdad. Madrid: Herder.

Rancière, J. (2006). Política, policía, democracia. Santiago de Chile: LOM.

Retamozzo, M. (2011). Tras las huellas de Hegemón. Usos de hegemonía en la teoría política de Ernesto Laclau. Utopía y praxis latinoamericana, 16(55), 39-57.

Roberts, K. (1995). Neoliberalism and the Transformation of Populism in Latin America. World Politics, (48), 82-116.

Roxboroug, I. (1984).Unity and Diversity in Latin America History. Journal of Latin America Studies, 1(16), 1-26.

Sartori, G. (2011). Cómo hacer ciencia política. España: Taurus.

Stavrakakis, Y. (2004). Antinomies of Formalism: Laclau's theory of populism and the lessons from religious populism in Greece. Journal of Political Ideologies, 9(3), 253-267.

Viguera, A. (1993). Populismo y neopopulismo en América Latina. Revista mexicana de sociología, (55), 49-66. 
Vilas, C. (1988). El populismo latinoamericano: un enfoque estructural. Desarrollo Económico, 28(111), 323-352.

Vilas, C. (2004). ¿Populismos reciclados o neoliberalismo a secas? El mito del "neopulismo" latinoamericano. Revista sociales y política, (22), 135-151.

Villacañas, J. L. (2010). The Liberal Roots of Populism. Centennial Review, 10(2), 151-182.

Weyland, K. (2001). Clarifying a Contested Concept: Populism in the Study of Latin American Politics. Comparative Politics, 34(1), 1-22.

Zîzêk, S. (2006). Against Populist Temptation. Critical Inquiry, (32), 551-574. 